\title{
Innovation, Proactive and Business Performance in SMEs
}

\author{
Primadona \\ \{pdmamarafif@gmail.com\} \\ Politeknik Negeri Padang, Kampus Limau Manis, Padang, Sumatera Barat
}

\begin{abstract}
This study aims to determine the effect of innovation and proactivity on business performance in embroidery, embroidery and weaving SMEs which are SMEs that are managed from generation to generation in West Sumatra. This research contributes to the business performance of SMEs, which generally stand for more than fifteen years, spread almost in all regions in West Sumatra. Research locations in West Sumatra involving eight regions that have handicraft SMEs. The number of research samples is 200 respondents with SME owner analysis unit. The research methodology is quantitative to find out how much influence the innovation and proactive variables have on business performance. Data analysis using SPSS program using a questionnaire instrument with survey methods. The results of the study revealed that the innovative and practical variables jointly had a significant effect on business performance by 0.436 or 43.6 percent while the rest were influenced by other factors not included in this study. The limitation of this research is that it only includes two factors that influence business performance in SMEs, namely innovation and proactivity, and for further research, it can add other variables such as the ability to cope with risk, business sustainability and competitive competition.
\end{abstract}

Keyword: SMEs, innovation, proactive, quantitative

\section{Introduction}

Developed countries strongly support the existence of SMEs because they are able to support the role of large industries [1]. Every company in the world is currently trying to find self-characteristics to be able to create competitive advantage in order to compete both new companies and old companies [2]. Thus increasing entrepreneurial skills by means of visionary behavior, innovative abilities, and proactive attitudes [3]. Based on these factors, the management of a company must be able to increase the search for new things and always innovate in order to continue to create new innovations for the company [4].

Innovation in entrepreneurship has a great influence, entrepreneurs as providers and users of innovation must be able to sacrifice so that the innovations found can be used to improve business performance. Entrepreneurs as SME owners must also be able to work closely with academics and scholars so that innovation discoveries get perfect results in improving business performance [5]. Proactive entrepreneurs also influence the ability of companies to be able to innovate in order to get superior products that can compete in order to improve company performance [6] Internationalization arrangements have called for rapid changes in technology, the important role of innovation has basically changed so that SMEs have the image to encourage innovation ridden by entrepreneurs [7].

The existence of SMEs is often associated with the emergence of innovative products that only require a short time to be able to spread their wings to compete [8]. But it often happens 
that SMEs take too long from their initial vision and mission and forget to make changes, even though there is no denying that there are currently many threats and competition that can quickly turn off businesses. Technological progress and the occurrence of human evolution certainly changes to be able to equalize the ability to be done immediately. Innovation and the desire or proactive attitude can not be eliminated if SMEs want to continue to exist. This should also be a focus for SMEs in dealing with changes in both the changes in tastes or substance of the management of SMEs. Consumers want products that are in accordance with the tastes of the time and certainly in providing them, SME owners must be able to fulfill them because this is one of the strategies that must be done by SMEs in facing competition in meeting the needs of consumers [9]. Innovating in the face of competition is one of the recognized ways to be able to always survive and become one of the leading [10].

Small and Medium Enterprises or SMEs are small businesses that have been able to sustain the economy in West Sumatra, Indonesia because the existence of large industries has not been seen yet. What has the potential to be seen is the role of innovation and the proactive nature of SMEs in facing competition. Many SMEs currently are businesses that are still managed from generation to generation. Maintaining the identity of SMEs and original products is fundamental for SMEs. The urgency of this research is that there are several types of SMEs that still have consistency both in producing products and in carrying out business management, such as embroidery, embroidery and weaving crafts in West Sumatra, west of Indonesia where these SMEs are SMEs that generally stand a very long time of at least 20 years and some even up to 70 years. The question is whether with the occurrence of very large changes currently in the business world make SMEs still able to improve business performance. The problem is that products produced using traditionally processed human labor can still compete without making changes such as innovation and managerial capabilities that are still outdated to be able to adjust. Currently the world is in turmoil with an era of creativity and innovation and this can be a challenge for SMEs in running their businesses. This paper would like to reveal whether innovation and proactivity have a contribution or influence on business performance, especially SMEs that have different functions from other SMEs because these SMEs are managed from generation to generation and carried out each in the traditional way. Absorption of labor for SMEs in Indonesia, especially in West Sumatra is very much, one SMEs is able to employ up to 70 people to produce products.

This paper consists of four parts, namely the first part reveals the reasons for the importance of this title discussed, the purpose of the study is explained clearly in order to find synchronization, the second part will explain the urgency of the subject so that it has the right reasons for further discussion and the third and fourth parts will explain the results of research and long discussions that have been conducted regarding proactivity, innovation and business performance in SMEs. Further research will be concluded from the discussion presented.

\section{Theoretical Background And Hypotheses Business Performance}

The company's performance is basically how the company manages the company by using available resources and having an impact on the company. Company performance must be measurable in order to provide information on company development and this will determine the direction of the strategy to be carried out by the company in order to be able to compete or 
improve the ability of the company. Performance can be defined as an activity that can be achieved by a person or group of people or organization that is adjusted to the authority and responsibility of each in managing resources to achieve the goals and targets set by the company and in achieving it legally without breaking the law and contrary to morals and ethics. In seeing the company's ability or performance, many measures are taken including assessing through financial statements, the number of sales or by looking at the company's position in the community. Performance is a matter of being the most important part of management and business research in a company.

\section{Innovation and Business Performance}

Innovation must be done by entrepreneurs if you want to be a winner in the competition. Entrepreneurs are people who are involved in innovating to produce a successful new business [11]. Because entrepreneurship and innovation are two interrelated things, creating innovation will be related to the provision of equipment and resources and also the availability of financial capabilities that can be provided by entrepreneurs [12][5]. In general, business performance is universal so it is interesting for researchers to always optimize findings to improve the results of business performance itself [7]. Therefore, the company must be able to have a master strategy and must also be able to integrate several existing resources and have the ability to compete in producing superior products that are carried out with the innovation process. Conduct an evaluation which is an integrated effect of proactive, innovation, and organizational capability capabilities on the ability and performance of SMEs and this will provide empirical evidence that impacts on the development of business performance theory with competitive advantage for SMEs in manufacturing industries in developing countries such as Indonesia [13].

There are two big views on the relationship of innovation and company performance raised by Geroski [7][14], namely the first view states that the creation of new products in the company will have an impact on competition and directly affect the company's internal performance which is only temporary. The second view states that the innovation process has an impact on company performance internally and externally because it can change the company fundamentally compared to companies that do not innovate. Therefore, innovation can improve company performance from the innovation products that are carried out so that it can compete with competitors and overall can change the ability or performance of the company.

\section{Hypothesis I: Innovation influences business performance}

\section{Proactiveness and Business Performance}

Proactive and innovation is an ability to be able to increase the ability of entrepreneurial orientation [15]. Proactive definitions reveal that innovative attitudes complement each other to improve performance capabilities [16]. A company that has a firm development strategy will be able to match the needs of innovation with available resources so that it can quickly improve company performance and the relationship between them: the role of innovation and proactivity can already be proven in the literature [15]. Implicitly, this explains two related things, namely the ability of organizations with the ability to be able to clearly describe the relationship between innovation, proactivity and company performance. In other words, the impact of proactive 
attitudes and innovation on company performance can be seen and understood through their role in developing organizational capabilities [17][18]. Other research empirically also found similarities that the innovation and proactive processes carried out by the company really helped the company in developing the company and would be able to improve the condition of the company [19]. This makes the writer can conclude in a hypothesis that proactively influences company performance.

\section{Hypothesis 2: Proactively influencing business performance}

\section{Methodology}

\section{Sample and Data Collection}

Survey through a structured questionnaire consisting of statements related to the company's proactivity, innovation, company performance designed. The survey was conducted among owners / managers of SME crafts embroidery, embroidery and weaving in the Western region of Indonesia between July and October 2019. Based on Data from the Central Statistics Agency (BPS) from the West Sumatra Small and Medium Enterprise Development Agency (MSMEs), Indonesia totals 600 Manufacturing SMEs for embroidery, embroidery and weaving crafts. Based on the guidance procedure as suggested by Gay \& Diehl in 1992, cluster sampling techniques were adopted to obtain the sample sizes needed for this study. The West Sumatra region consists of 8 regions. Therefore, the study population was categorized into eight groups. The questionnaire was distributed through a self-managed approach with the help of research assistants. A total of 200 questionnaires were distributed based on regions that had been designated as research locations. This study uses Regression data analysis tools using SPSS version 23 application to determine the effect of each dependent variable on the independent.

\section{Measures}

Measurement tools or instruments for proactive and innovative adapted from Zhang et al [20]. The commonly adopted approach to measuring company performance in terms of small and medium enterprises is the perception of the owner / manager because in many cases the data needed for objective performance measurement is not accessible [7][9]. So the authors conclude that in this study the performance measurement scale uses eight items adapted from [21]. The participants were asked based on their perceptions to assess the performance of their company over the past five years. Research carried out using instruments with survey methods. The questionnaire uses a Likert scale by having choice 5 which is strongly agree, agree, neutral, disagree and strongly disagree.

\section{Discussion and Findings}

\section{Characteristics of Respondents}

This research has several characteristics of respondents, including based on gender, age, number of turnover, company establishment and education of SME owners. This is needed to provide complex information about SMEs that will be used as research samples.

\section{Based on age}




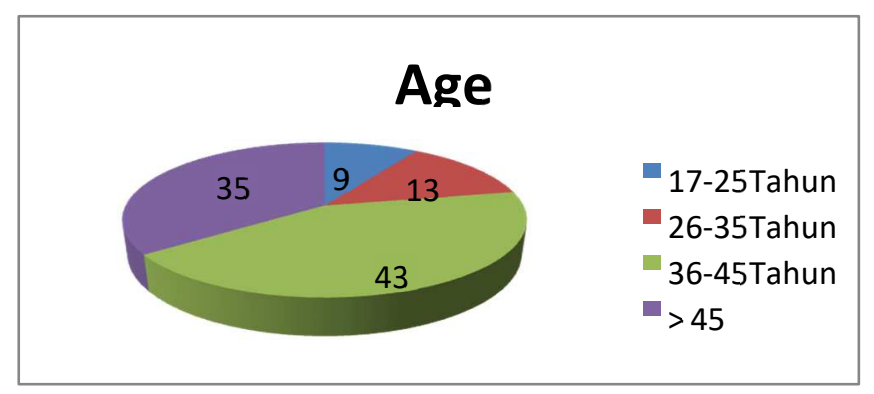

Fig. 4. Based on age

Based on age, it can be seen that SME owners are generally elderly, with an average of over 35 years, which is around 78 percent, while the rest are below 35 years. This is a result of SMEs studied are SMEs engaged in the field of embroidery crafts which are original works of the region and are managed from generation to generation. And in general it is the second or third generation and only a few are beginner businesses.

\section{Based on Education}

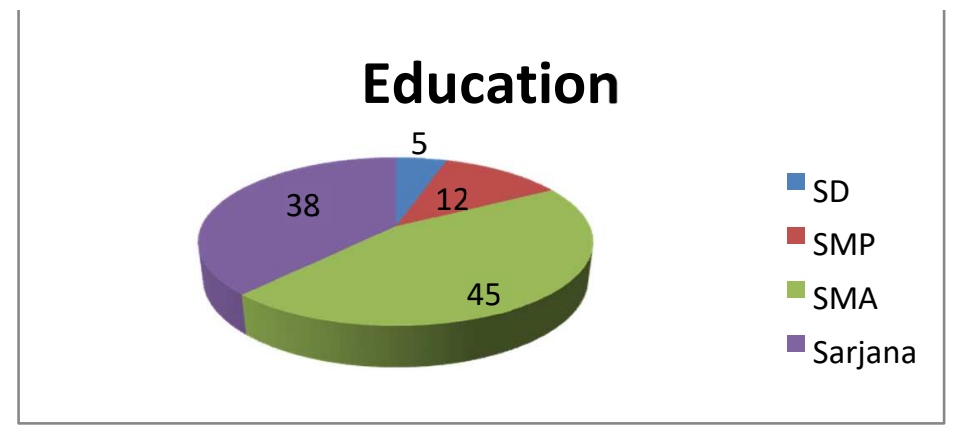

Fig. 2. Based on Education

Based on education, SME owners generally have an average high school education (high school) and 38 percent are undergraduate. While around 17 percent are elementary school (elementary school) and junior high school (junior high school).

\section{Based on Gender and Length of Establishment of Business}




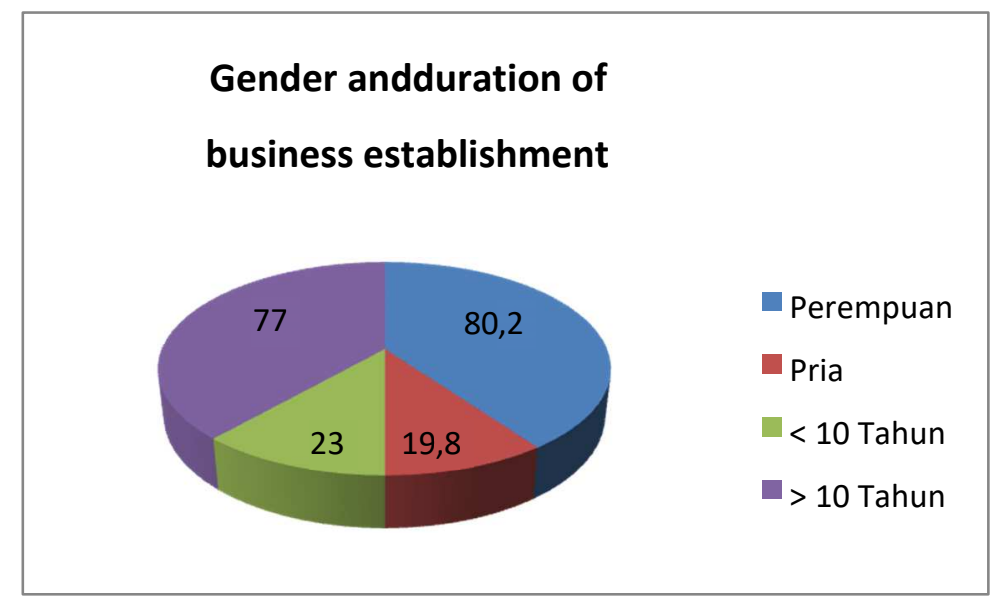

Fig. 3. Based on Gender and Length of Business Establishment

Based on the picture above, it can be seen that for the sexes, the dominant one is women because in West Sumatra the Matrilinel system adheres to the mother's lineage so that it is natural for SME owners to be managed for generations done by women and the rest by men. Whereas for a long time standing, in general the business stood for a long time, namely over 10 years with a percentage of 77 percent. Based on the characteristics of the respondents, in general, the business is managed by women with an average high school and undergraduate education. The running time is generally over 10 years with the age of the SME owner being over 35 years.

\section{Finding}

Based on the data analysis, the results state that the model that we tested through the hypothesis we set can be done because based on the terms of the classic assumption of linear regression with OLS, a good linear regression model is free from the presence of multicollinearity. Thus, the above model has been freed from the existence of multicollinearity. In the model also does not occur multicollinearity marked VIF values in the table no more than 5 to 10 . In the processing of VIF values only 1, 862 thus processing can be continued. The results can be seen in Table 4.1

Tabel 4. Processed Data Results Coefficients ${ }^{\mathrm{a}}$

\begin{tabular}{|c|c|c|c|c|c|c|c|c|c|c|c|}
\hline & \multirow[b]{2}{*}{ Model } & \multicolumn{2}{|c|}{$\begin{array}{c}\text { Unstandardized } \\
\text { Coefficients }\end{array}$} & \multirow{2}{*}{$\begin{array}{c}\begin{array}{c}\text { Standardized } \\
\text { Coefficients }\end{array} \\
\text { Beta }\end{array}$} & \multirow[b]{2}{*}{$\mathrm{t}$} & \multirow[b]{2}{*}{ Sig. } & \multicolumn{3}{|c|}{ Correlations } & \multicolumn{2}{|c|}{ Collinearity Statistics } \\
\hline & & B & Std. Error & & & & Zero-order & Partial & $P$ & Tolerance & VIF \\
\hline 1 & (Constant) & 40,527 & 7,958 & & 5,092 &, 000 & & & & & \\
\hline $\mathrm{X} 2$ & & 3,184 & ,758 & ,309 & 4,203 &, 000 & ,588 & 289 & ,227 & ,537 & 1,862 \\
\hline $\mathrm{X} 1$ & & 3,638 & ,653 & ,410 & 5,571 &, 000 & ,620 & ,371 & ,300 & ,537 & 1,862 \\
\hline
\end{tabular}

a. Dependent Variable: Y 
To see the normality test results can be seen from the Normal P-P plot below. It should be reminded that the normality assumption referred to in the classical assumptions of the OLS approach is the residual (data) formed by the linear regression model normally distributed, not the independent variable or the dependent variable. Criteria for a residual (data) is normally distributed or not with the Normal P-P plot approach can be done by looking at the distribution of points in the picture. If the distribution of these points is close to or close to a straight line (diagonal) then it is said that the residual (data) is normally distributed, but if the distribution of these points away from the line is not normally distributed. Based on Figure 4, it can be said that the model is normally distributed.

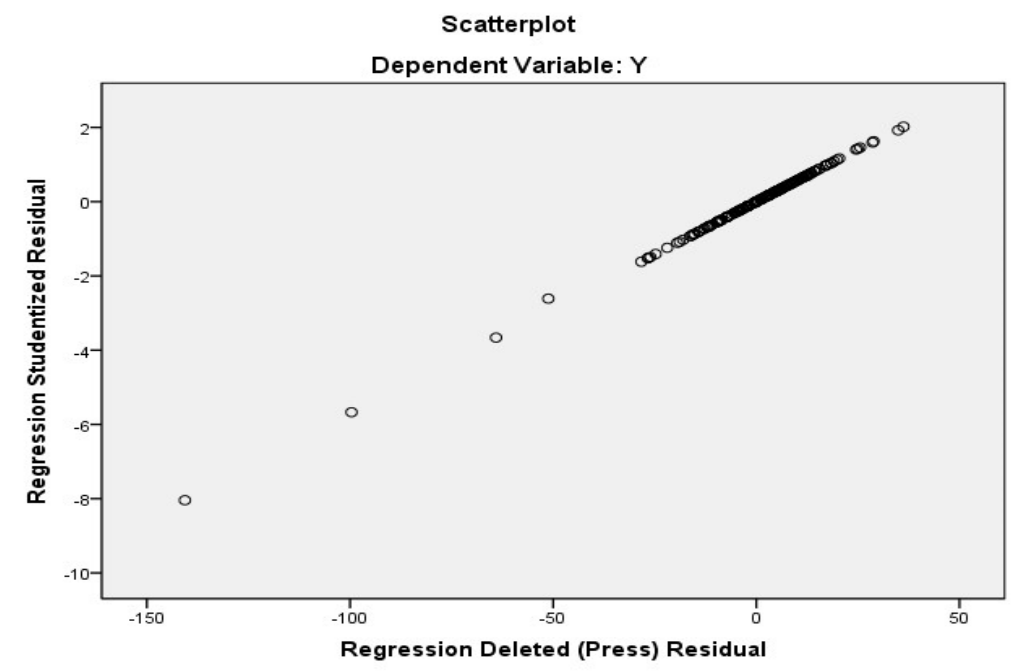

Fig. 4. Normally Distributed

\section{Model Reliability Test (Test F)}

The model reliability test or the model feasibility test or more popularly referred to as the F test (some also call it the simultaneous test of the model) is the initial stage of identifying a regression model that is estimated to be feasible or not. Decent (reliable) here means that the estimated model is feasible to use to explain the effect of independent variables on the dependent variable. The name of this test is referred to as the F test, because it follows the F distribution following the testing criteria such as One Way Anova. . F arithmetic (SPSS output shown in column sig.) Is smaller than the error rate (alpha) 0.05 (which has been determined) then it can be said that the estimated regression model is feasible, whereas if the value of prob. F arithmetic greater than the error rate of 0.05 , it can be said that the estimated regression model is not feasible.

F test results can be seen in the ANOVA table below. Prob value F count is seen in the last column (sig.). Based on the processed data, the Sig value is 0.000 so that the model is feasible to be tested because the requirements are met.

Tabel 5. ANOVA ${ }^{b}$

\begin{tabular}{lllllll}
\hline Model & Sum of Squares & df & Mean Square & F & Sig. \\
\hline
\end{tabular}




\begin{tabular}{llrrrrr}
\hline & Regression & 45591,197 & 2 & 22795,598 & 75,012 &, $000^{\mathrm{a}}$ \\
\cline { 3 - 6 } 1 & Residual & 58954,986 & 194 & 303,892 & \\
\cline { 3 - 6 } & Total & 104546,183 & 196 & & \\
\hline
\end{tabular}

a. Predictors: (Constant), X1, X2

b. Dependent Variable: Y

Based on the results Prob value. The calculated F (sig.) In the table above is 0,000 less than the 0.05 significance level so that it can be concluded that the estimated linear regression model is feasible to use to explain the effect of Innovation and Proactivity on the Business Performance dependent variable.

\section{Regression Equation}

Based on the results contained in the table, the regression equation model of this study is:

$$
\begin{aligned}
& \mathrm{Y}=\mathrm{a}+\mathrm{b}_{1} \mathrm{X}_{1}+\mathrm{b}_{2} \mathrm{X}_{2} \\
& \mathrm{Y}=40,527+3,184 \mathrm{X}_{1}+3,638 \mathrm{X}_{2} \text { Explanation: } \\
& \mathrm{Y}, \quad=\text { Business Performance }=\text { constanta } \\
& \mathrm{a}=\text { regression coefficient } \\
& \mathrm{b}_{1}, \mathrm{~b}_{2} \quad=\text { Innovation }(\%) \\
& \mathrm{X}_{1} \quad=\text { Proactive }(\%) \\
& \mathrm{X}_{2} \quad
\end{aligned}
$$

The regression equation above can be explained as follows:

a. A constant of 40,527; meaning that if the innovation (X1) and proactive (X2) value is 0 , then the business performance ( $Y^{\prime}$ ') value is 40,527.

b. Innovation variable regression coefficient (X1) of 3,187; meaning that if other independent variables have a fixed value and Innovation has increased $1 \%$, then business performance ( $Y^{\prime}$ ') will increase by 3,184 .

c. Proactive variable regression coefficient (X2) of 3,638; this means that if other independent variables have a fixed and proactive value that has increased $1 \%$, then business performance ( $\left.\mathrm{Y}^{\prime}\right)$ will increase by 3,638. Positive coefficient means that there is a positive relationship between proactivity and business performance, the more proactive attitude increases, the more business performance increases.

\section{Multiple Correlation Analysis (R)}

This analysis is used to determine the relationship between two or more independent variables (X1 and $\mathrm{X} 2$ ) to the dependent variable $(\mathrm{Y})$ simultaneously. $\mathrm{R}$ value ranges from 0 to 1 , the value is getting closer to 1 means that the relationship is getting stronger, on the contrary the value is getting closer to 0, the relationship is getting weaker. Based on the results of the analysis it can be seen the relationship between variables or values (R) in the table below. 
Tabel 5. Model Summary ${ }^{\mathrm{b}}$

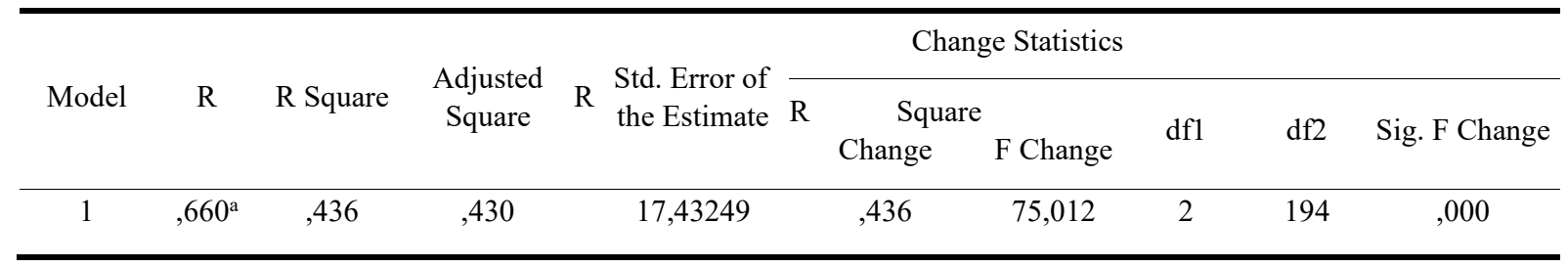

a. Predictors: (Constant), X1, X2
b. Dependent Variable: Y

Based on the table above obtained $\mathrm{R}$ numbers of 0.660 . This shows that there is a strong relationship between innovation and proactivity on business performance.

\section{Determination Analysis (R2)}

Analysis of determination in multiple linear regression is used to determine the percentage contribution of the influence of the independent variable $(\mathrm{X} 1, \mathrm{X} 2, \ldots \ldots \mathrm{Xn})$ simultaneously to the dependent variable (Y). Based on the table above, the R2 (R Square) figure is 0.436 or (43.6\%). This shows that the percentage contribution of the influence of independent variables (Innovation and Proactivity) on the dependent variable (business performance) was 43.6 percent. Or the variation of the independent variables used in the model (Innovation and proactivity) can explain 43.6 percent of the variation of the dependent variable (business performance). While the remaining 56.4 percent is influenced or explained by other variables not included in this research model.

\section{Conclusion and Implementation}

This study revealed that innovation and proactivity significantly influence business performance. This means that embroidery and embroidery SMEs that have been managed from generation to generation are proactive and innovative contributions of 43.6 percent in influencing business performance while the rest is influenced by other factors. The limitation of this study is that the data collection is still using a questionnaire and it is hoped that further research can be carried out by interview and observation to be able to create added value in this finding

\section{References}

[1] R. Zacca and M. Dayan, "Linking Managerial Competence to Small Enterprise Performance within The Dynamic Capability Logic," J. Small Bus. Enterp. Dev., vol. 25, no. 2, pp. 256-276, 2018.

[2] R. Chandy and O. Narasimhan, "How Micro-Entrepreneurs Could Change The World," Business Strategy Review, vol. 22, no. 1. pp. 52-55, 2011.

[3] M. A. Dean, C. L. Shook, and G. T. Payne, "The Past, Present, and Future of Entrepreneurship Research: Data Analytic Trends and Training," Entrep. Theory Pract., no. 6, pp. 601-618, 2007.

[4] M. L. Harris and S. G. Gibson, "Examining the Entrepreneurial Attitudes of US Business Students," Educ. Train., vol. 50, no. 7, pp. 568-581, 2008.

[5] G. Currie, M. Humphreys, D. Ucbasaran, and S. Mcmanus, "Entrepreneurial Leadership in The English Public Sector: Paradox or Possibility?," Public Adm., vol. 86, no. 4, pp. 987-1008, 2008. 
[6] C. Angkanurakbun and S. Wanarat, "The Mediating Effect of Product Innovation Capability on Entrepreneurial Pro-activeness and Hotel Performance," Int. J. Innov. Manag., vol. 20, no. 3, pp. 1-21, 2016.

[7] V. K. Gupta and S. Batra, "Entrepreneurial Orientation and Firm Performance in Indian SMEs: Universal and Contingency Perspectives," Int. Small Bus. J., vol. 34, no. 5, pp. $1-23,2015$.

[8] J. G. Covin and D. Miller, "International Entrepreneurial Orientation: Conceptual Considerations, Research Themes, Measurement Issues, and Future Research Directions," Entrep. Theory Pract., vol. 38, no. 1, pp. 1-34, 2013.

[9] J. G. Covin and W. J. Wales, "The Measurement of Entrepreneurial Orientation," Entrep. Theory Pract., vol. 36, no. 4, pp. 1-26, 2011.

[10] M. Ashena, N. Asgari, A. M. Saleh, and D. Ghafouri, "The Role of Organizational Culture in The Knowledge Management Process," 2014.

[11] M. Meyer, "Academic Entrepreneurs or Entrepreneurial Academics? Research-based Ventures and Public Support Mechanisms," $R$ D Manag., vol. 33, no. 2, pp. 107-115, 2003.

[12] C. C. Cogliser and K. H. Brigham, "The Intersection of Leadership and Entrepreneurship: Mutual Lessons to be Learned," Leadersh. Q., vol. 15, no. 6, pp. 771799, 2004.

[13] M. E. Agwu, "Analysis of The Impact of Strategic Management on The Business Performance of SMEs in Nigeria," Acad. Strateg. Manag. J., vol. 17, no. 1, pp. 1-20, 2018.

[14] P. Geroski and S. Machin, "Do Innovating Firms Outperform," Bus. Strateg. Rev., vol. 3, no. 2, pp. 79-90, 1992.

[15] G. T. Lumpkin and G. G. Dess, "Clarifying the Entrepreneurial Orientation Construct and Linking it to Performance," Acad. Manag. J., vol. 21, no. 1, pp. 135-172, 1996.

[16] J. Tang, Z. Tang, and J. A. Katz, "Proactiveness, Stakeholder-Firm Power Difference, and Product Safety and Quality of Chinese SMEs," Entrep. Theory Pract., vol. 38, no. 5, pp. 1-29, 2013.

[17] K. M. Eisenhardt and J. A. Martin, "Dynamic capabilities: What are they?," Strateg. Manag. J., vol. 21, no. 10-11, pp. 1105-1121, 2000.

[18] D. J. Teece, G. Pisano, and A. Shuen, "Dynamic Capabilities and Strategic Management," Strateg. Manag. J., vol. 18, no. 7, pp. 509-533, 1997.

[19] T. C. F. Ho, N. H. Ahmad, and T. Ramayah, "Competitive Capabilities and Business Performance among Manufacturing SMEs: Evidence from an Emerging Economy, Malaysia," J. Asia-Pacific Bus., vol. 17, no. 1, pp. 37-58, 2016.

[20] H. Zhang, T. Zhang, H. Cai, Y. Li, W. Wei Huang, and D. Xu, "Proposing and validating a five-dimensional scale for measuring entrepreneurial orientation: An empirical study," J. Entrep. Emerg. Econ., vol. 6, no. 2, pp. 102-121, 2014.

[21] J. Spillan and J. Parnell, "Marketing Resources and Firm Performance Among SMEs," Eur. Manag. J., vol. 24, no. 2-3, pp. 236-245, 2006. 